\title{
HOMOPHONIC PREJUDICES
}

\author{
MANUEl García-CARPinTERo \\ Departamento de Lógica, Historia y Filosofía de la Ciencia \\ Universidad de Barcelona \\ m.garciacarpintero@ub.edu
}

SUMmaRY: I critically discuss some aspects of Mark Sainsbury's Reference without Referents, from an otherwise sympathetic viewpoint. My objections focus on the adequacy of the truth-conditional framework that Sainsbury presupposes. I argue that, as semantic theories, truth-conditional accounts are both too ambitious, and too austere to be fully explanatory, and that both problems have consequences for an account of reference. The latter problem has to do with the difficulties to capture in a truth-conditional framework the descriptive contribution of indexicals and, in my view, proper names. The former has to do with the non-semantic contribution of context to the determination of truth-conditions in general and reference in particular.

KEY WORDS: reference, truth-conditions, presuppositions, indexicals, vacuous terms

RESUMEN: En este artículo discuto críticamente algunos aspectos del libro de Mark Sainsbury Reference without Referents, desde una perspectiva por lo demás próxima. Mis objeciones se centran en la adecuación del marco que Sainsbury presupone: la semántica de condiciones de verdad. Argumento que tales propuestas son, en tanto que teorías semánticas, a la vez demasiado ambiciosas y demasiado austeras para ser genuinamente explicativas, y que ambos problemas tienen consecuencias en lo que respecta a la explicación de la referencia. El segundo problema tiene que ver con las dificultades para representar la contribución descriptiva de los deícticos y, en mi opinión, de los nombres propios también en el marco de condiciones de verdad. El primero tiene que ver con la contribución no semántica del contexto a la determinación de las condiciones de verdad en general y la referencia en particular.

PALABRAS CLAVE: referencia, condiciones de verdad, presuposiciones, deícticos, términos vacíos

Reference without Referents is a concentrated, tightly argued defense of a theory of reference going by the same name, henceforth RWR. Against the prevailing Millian orthodoxy, RWR allows empty names to be intelligible, so that the semantic value of a name cannot be identified with its referent. However, RWR tries to steer away from traditional Fregeanism and its identification of the meaning of a name with a description. RWR assumes a Davidsonian truth-theoretic framework, which compositionally delivers truth-conditions as semantic values for declarative sentences, and reference-conditions for referring expressions, in both cases as close as possible to the ideal of homophony, thus renouncing any reductive ambitions. The reference 
condition for "Hesperus" and "Vulcan" is given by axioms such as these:

(1) For all $x$, "Hesperus" refers to $x$ iff $x$ is Hesperus.

(2) For all $x$, "Vulcan" refers to $x$ iff $x$ is Vulcan.

RWR assumes in the metalanguage a free logic of the "negative" sort championed by Burge (1974), which renders claims like (2) true; on the other hand, and unlike (1), the replacement of "Hesperus" by "Phosphorus" in the right-hand-side of (1) is held to produce an inadequate non-interpretative theory.

To articulate and elaborate RWR, after a historical stage-setting discussing the views of Mill, Frege, Russell, Kripke, Evans and McDowell, the book examines the main issues related to its topic: the working of proper names, indexicals and demonstratives, definite descriptions, plural referring expressions; reference in fiction; singular concepts in thought. Nonetheless the book is short and in fact is a joy to read: no sentence is expendable, every word seems to have been chosen thoughtfully. Readers with many different theoretical leanings will learn from its carefully stated claims and arguments.

I myself happen to share the main claims of the book — although, as it will transpire, the theoretical foundations that on my view underpin them are closer to traditional, descriptivist Fregeanism than to Sainsbury's RWR. To be more specific, except for a few qualms concerning the kind of free-logic I prefer (which may depend on the more foundational theoretical differences already mentioned), I share the claims in this useful summary:

a referring expression is one that "purports to refer": it needs to succeed if an unembedded occurrence of the expression is to express a truth; it may fail to refer without detriment to intelligibility; a correct semantics will associate it with a reference condition rather than with a referent; a semantic theory for such expressions will be set within free rather than classical logic; truth conditions for sentences of the form " $t$ is $F$ ", where " $t$ " is such a pronoun, will be Ockhamist (ones which do not require the existence of a referent for falsehood). (pp. 130-131)

Here I will focus on raising some concerns in relation to these main discrepancies.

My main doubts centre on the truth-conditional framework: I am uncertain whether the austere resources of such proposals could really support the claims about reference definitive of $R W R$. The 
truth-theoretic approach is advertised in that "it deflates semantic ambition, and it helps restrain ad hoc proposals" (p. 47). The second virtue derives from the fact that "this theoretical task gives us a check on our theoretical grasp of the compositional character of the language" (pp. 39-40). The first "is manifest in the acceptance of 'homophonic' theorems, in which truth conditions for the object language expression are specified by reusing these very expressions in the metalanguage" (p. 47).

My departing point is the concern whether an adequate "check on our theoretical grasp" of compositionality capable of claiming the first merit should have the austerity advertised as the second virtue. As we will see, Sainsbury himself acknowledges that it cannot, but it will be helpful to present the reason why not against the background of a more general problem. Sainsbury's acknowledgement concerns well-known problems posed to the aspirations of truth-conditional approaches by context-dependent expressions: these expressions show that the approach falls short of what we need from a compositional semantic account, and, perhaps paradoxically, also that it is too ambitious. I think that, in both respects, the case of indexicals is just an instance of more general problems.

Sainsbury refers to Larson and Segal 1996, as a good indication of how far the Davidsonian truth-theoretic framework can take us in the direction of providing an explanatory account of the compositional structure of natural languages. My experience in teaching graduate courses on formal semantics indicates, however, that this otherwise impressive manual may also have the counterproductive effect of making glaringly obvious the Procrustean nature of the undertaking, when one compares the cumbersome derivations that its ontological paucity imposes on its students with corresponding ones in equally pedagogical manuals, such as Heim and Kratzer 1998, covering a similar range in introducing its readers to the rival, model-theoretic approach inspired instead by Montague's work. The comparison shows, I think, that the explanatory deficits of truth-theoretic semantics do not reduce to a comparative lack of perspicuity - a perhaps acceptable side effect of ontological austerity - but involve in addition real explanatory insufficiencies; the one I am interested in here concerns difficulties for capturing the differential semantic import of conventional implicatures and lexically-based presuppositions. Consider:

(3) Even John could prove the Completeness Theorem.

(i) John could prove the Completeness Theorem. 
(ii) It is comparatively improbable that John could prove the Completeness Theorem.

Grice (1989, pp. 121, 361) maintained that, in his favored sense of "say", (3) says that (i) while it does not say, but merely indicates, that (ii); as a result, utterances such as (3) can be correctly counted as true, even if what corresponds for them to (ii) is false, as for instance in "Even Gödel could prove the Completeness Theorem". Utterances such as this should be classified as somehow inappropriate or infelicitous, rather than false. Barker (2003) defends the Gricean view, thereby objecting to theories of meaning that seek to reduce linguistic meaning to truth-conditions. He argues, with Grice, that while (i) is what is said by (3), and thus what determines its truthcondition, not just (i), but also (ii) is part of (2)'s semantic content, "the content it possesses by virtue of linguistic rules and context, and upon which logical particles may potentially operate" (Barker 2003, p. 2). He provides in my view convincing evidence for the latter claim, the semantic embeddability of what is indicated, or conventionally implicated, as part of the content to which some operators are sensitive (Barker 2003, pp. 8-13). Similar points could be made on the basis of presupposition-inducing lexical items and structures, such as "stop", "again", the cleft and pseudo-cleft constructions, etc. On the other hand, Heim and Kratzer (1998) show how these semantic facts can be properly captured in their alternative semantic framework.

With this in mind, let us consider now the case of referential expressions, starting with indexicals. In previous works (2000, 2006a), I have argued that, while referential expressions such as indexicals and proper names contribute their referents to what is said - the content asserted in utterances of simple subject-predicate declarative sentences where they occur, as direct-reference theorists contend-, some reference-fixing descriptive materials contribute to merely indicated conventional implicatures, and thus to semantic content, against the most radical tenets of those theorists. Following Stalnaker (1974, 1978, 2002), I analyze there the relevant Gricean conventional implicatures — merely indicated but nonetheless semantic contentsas pragmatic presuppositions, as opposed to semantic presuppositions (requirements for the truth of the sentence encoding it and its negation). The relevant contents are semantic (part of what is expressed), in that they are part of the conventional meaning of some expressions, they account for the felt validity of some inferences, they embed under some operators, and so on. But they should be 
analyzed in terms of the pragmatic notion of what speakers believe to be part of the common ground they accept, as argued by Stalnaker, because such an explication is appropriately more flexible. It allows that in some cases the fact that the indicated content fails to obtain (including some claims about Vulcan, such as its being self-identical) is compatible with the truth or falsity of the utterance; while in some other cases this is not so. The view also allows for a theoretically more satisfactory account of presupposition projection, and for there being a form of presupposition cancellation.

Of course, this is not the place to argue for my own views; I cannot give any details of how such an account would go which match what RWR offers, and in any case there may well be better alternative accounts in the same spirit. The idea behind the above outline was just to have what I hope is a useful contrast, with respect to which I can now press the questions that worry me. Indexicals pose a problem for truth-conditional approaches; as Kaplan (1989) rightly emphasized, their contribution to the truth-condition of utterances including them depends on context, so that, if we attempt a homophonic specification, the indexical used on the right hand side will typically have a different truth-conditional import than the one mentioned on the left hand side. The standard solution, suggested by Burge and adopted by Larson and Segal (1996) and others, is to require from the semantic theory only conditionalized truth-conditions, such as:

(4) For all $x$, if in uttering "That is $F$ " the speaker used "that" to refer to $x$, her utterance is true iff $x$ satisfies $F$.

Sainsbury accepts this (p. 55); in fact, he generalizes this result. The empirical adequacy of truth-theories as semantic theories of natural languages is measured by the extent to which they are sufficient for the theoretician to interpret speakers - in particular, to understand what they say with their assertoric utterances - thereby making sense of their actions. Now, relativized truth-conditions such as (4) at most give us knowledge of the meaning common to different utterances of an indexical, something like what Kaplan (1989) calls "character", which falls short of what is needed for interpretation. ${ }^{l}$ But going beyond this is problematic, because reference-determination might well depend on facts which transcend what a semantic theory is in a

\footnotetext{
${ }^{1}$ I say "at most" because of the doubts I will later cast whether the truth-theoretic framework can capture, say, the character-like information that the referent of "she" ought to be female.
} 
position to offer — which is why I said before that truth-conditional theories are not only insufficient (in not accounting for lexically-based presuppositions) but also too ambitious.

The problem here is a particular case of what contemporary "contextualists" such as Travis, Recanati and others have emphasized, that "the ordinary 'meaning' of expressions falls short of what is required to determine truth conditions" ( $R W R$, p. 50). Specifically applied to the case of indexicals, the problem is that the determination of their referents in context may "involve the exercise of general cognitive abilities" (p. 158) in such a way that it "is not susceptible to axiomatization" and "must come from outside the semantic theory" (p. 57). Sainsbury suggests that understanding indexical utterances might consist in the ability to provide accurate ascriptions of what is said with them, of their truth-conditions, which in these cases can only be properly specified relative to a scene-setting condition, as in (5); and this ability might be based in implicit knowledge of another example of such duplex "scene/content" structure such as (6) - a correct instantiation of the conditional (4) provided by the semantic theory:

(5) Pointing at Smarty Jones, John said that he was a winner.

(6) John's utterance of "That is a winner", thereby using "that" to refer to Smarty Jones, is true iff it satisfies "it is a winner".

This is consistent with RWR, because dual scene/content structures could be felicitously used even in cases in which the speaker used an empty term (pp. 151-152, 166-168).

Kaplan (1989) argued that indexicals and demonstratives are "directly referential", meaning by this that no descriptive indication of how the referent is thought of in utterances including them goes into an accurate specification of what is said. As Sainsbury points out, if singular truth conditions of this kind are "all that needs to be known for understanding, nothing about how the object was thought of need be known in understanding. This does justice to Kaplan's claim that such expressions are "directly referential" " $(R W R$, p. 162). However, he correctly points out that "when all goes as well as possible, an interpreter's way of identifying the referent is constrained. Hence for the interpreter to know a singular truth condition is not enough for everything to go as well as possible in interpretation" (p. 162).

Let me now formulate my objections, which articulate my perception of Sainsbury's reaction to the difficulties posed by indexicals to 
truth-theoretic accounts as somehow cavalier. In both cases - their apparent insufficiency and their apparent excessive ambition- he responds that the truth theoretic account operates under some kind of "idealization"; but I cannot really see what is so ideal about the idealizations. I will discuss the two problems in turn.

Acknowledging the first, Sainsbury says: "The recognition of indexicality has a substantial effect on truth-theoretic views. While homophony remains some kind of ideal, marking the fact that within this approach to meaning there is no attempt to reduce specific contents to others, it will rarely be achieved, thanks to the degree to which our language is indexical" (p. 56). Everybody should agree that excessive reductive ambitions are out of place: it should be possible to provide a semantic theory for our native language in that same language, enlarged with whatever resources are theoretically required; given that there cannot be any question that we already understand the metalanguage, it is in principle an acceptable option to use homophonic axioms, and in some cases that may well be what we should do. But why is homophony an ideal? If it is false that homophonic theories account for our language mastery, how can this falsehood nonetheless constitute any ideal?

To put the question in a less jocular manner: the knowledge that language mastery provides is implicit, also, as we have seen, on Sainsbury's view; why should we not expect that an explicit theoretical statement of that knowledge goes beyond homophony, even if it still falls short of unattainable reductive dreams? Speakers have implicit knowledge of the fact that the truth-conditional contribution of "now" depends on context; there is no other way of making explicit this implicit knowledge in a theoretically sophisticated way (assuming this is possible at all) than by mentioning tokens or utterances of expressions, and features of context on which the truth conditional import depends, in unobvious ways inescapably departing from homophony.

This is where the comparison with the presuppositional account mentioned above (or any other, similarly putting aside homophonic aspirations) helps to make my case. Larson and Segal (1996, pp. 211212) discuss whether accurate conditionalized axioms for complex demonstratives like "that horse" or simple ones such as "she" should be such that the information that the referent is, respectively, a horse, and female, ends up constituting the truth conditions of utterances including them (by appearing on the right hand side of the biconditionals in the consequent). I agree with their contention that it should 
not. However, apparently unlike them, I think that a semantic theory should nonetheless systematically capture what I take to be the fact about speakers' semantic competence, that the referent of those expressions is semantically constrained to be a horse and a female, respectively; and Sainsbury appears to concur here, for this is, I think, part of what he has in mind in saying that "an interpreter's way of identifying the referent is constrained" in a passage already quoted. The question is, how could a truth-conditional semantic theory capture this fact? How should the theory register the point that the referent of "she" should be female "when all goes as well as possible" ?"2

In fact, it is not so difficult to envisage ways of doing so; for instance one might design the theory so that it ends up delivering conditionalized ascriptions of truth conditions and what is said such as (7) and (8) - thereby granting something to presuppositional views, while also making glaringly obvious why reductive ambitions are out of place (see also Borg 2004, ch. 3):

(7) John's utterance of "She is $F$ ", made while presupposing that $x$ was the contextually relevant female when he uttered "she", is true iff $x$ satisfies "it is $F$ ".

(8) Presupposing that Margarita was the contextually salient female when he uttered "She is Mexican", John said that she was Mexican.

But these possibilities only make vivid the theoretical tension between subscribing the ideal of homophony, on the one hand, while appealing to non-homophonic conditionalized ascriptions on the other. If homophony is a theoretically well-justified ideal, then the conditionalized truth-conditions are $a d h o c$, an expedient to avoid immediate refutation unjustified in the theory's own proprietary terms, hence explanatorily idle; if, on the other hand, the theorist can come up with explanatorily adequate justifications for the conditionalized truth-conditions, incorporating in a systematic way the lexicallybased constraints on the adequate interpretation of indexicals and so

${ }^{2}$ A referee asked, "why can't Sainsbury argue that his theory could register the point that she should refer to a female in terms of speakers' abilities to choose the right sort of truth-conditions, namely, ones that involve referents which are female?" I am assuming here that a blanket appeal to abilities would not be enough, that these are specifically linguistic abilities, which a correct semantic theory should account for. 
on (perhaps along the lines needed to encompass (7) and (8)), then homophony is no ideal.

The accusation of ad hoc-ery can be further extended to the comparatively dissimilar way in which the theory (both RWR and Larson and Segal's (1996) more elaborated account) treats proper names and indexicals. No conditionalized truth-conditions are envisaged for proper names; however, Sainsbury acknowledges that their interpretation depends on context too, locating their context-dependence in an intermediate point - between pure indexicals and demonstratives such as "that" - on a scale of conventionally more or less strictly regulated reference determination (p. 58). In fact, one could argue that a version of a truth-theoretic account systematically incorporating the resources needed to deliver ascriptions such as (7) could just as well provide conditionals such as this:

(9) John's utterance of "Aristotle is $F$ ", made while presupposing that $x$ was the contextually relevant person named "Aristotle" when he uttered it, is true iff $x$ satisfies "it is $F$ ".

Sainsbury"s own rendition of the "chain of communication" account of reference determination for names in sections 3.5-3.7 (the most detailed and convincing I know of) could then be relied on, in order to provide a non-circular explanation of the property being named in a context assumed here. Sainsbury in fact contends that there is an asymmetry in the understanding of proper names and indexicals; in the second case, as we saw, understanding consists in possessing implicit knowledge of the conditionalized reports of what is said we are already familiar with, while in the case of proper names it merely consist in "engagement in a naming practice" (p. 155). But I fail to see why, even if one can make sense of such a difference in the interpretation of the expressions (which I doubt), it should be reflected in the asymmetric way we are discussing when it comes to the general provisions the theory makes for them.

In convincingly arguing against the direct-reference and the EvansMcDowell differential treatment of names with and without referents, Sainsbury appeals to the following principle: "A good theory's theoretical categories will match the natural categories of the language for which it is a theory" (p. 95). To the extent that proper names and indexicals constitute one such natural category (which Sainsbury seems to accept, the category being one identifiable "by its role in sentences" (p. 94)), the objection also applies to an account like his, 
which strives to preserve the ideal of homophony for proper names, but relinquishes it for indexicals.

Let me sum up this first set of reservations with respect to Sainsbury's appeal to idealization in dealing with the first, insufficiency problem for truth-theoretic accounts. Sainsbury concurs with Davidson that the allegedly appealing feature of the account - that, in contrast with rival Montague-inspired proposals, "it does not treat meanings as entities" — is not motivated by ontological prejudice, but rather by explanatory lucidity: meanings and intensional entities "have no demonstrated use in a theory of meaning" (p. 52), which is what homophony should establish. However, given that the account has to begrudgingly relinquish homophony, and given that the best worked-out accounts of the cases for which this must be conceded unsparingly trades in intensional entities (context understood as sets of propositions, features thereof, tokens and their types, and so on and so forth), the reluctance manifested in still calling homophony an "ideal" - thereby compromising the theoretical legitimacy of its non-homophonic proposals - suggests to me that it can only be philosophical prejudices which are somehow operating.

I will move now to Sainsbury's second appeal to idealizations, now in confronting the second problem posed by indexicals, the over-ambitiousness of truth-theoretic proposals. In response to the contextualist considerations, I (2006b) have suggested that semantic theories should confine themselves to minimal goals, which, unlike Borg (2004), I take to involve relinquishing the objective of ascribing truth-conditions to utterances: semantics should just be "charactersemantics", assuming a suitable generalization of Kaplan's notion; I argued that this is compatible with semantics providing the "check on our theoretical grasp of the compositional character of the language" that Sainsbury and Borg advertise for truth-theoretic accounts. Pagin and Pelletier (2007) provide a precise account of a suitable notion of compositionality, compatible with widespread contextual intrusions in the composition in the context of fully-fledged truth-conditional interpretations, along the lines of the one I envisaged.

I do not think that Sainsbury would disagree with much of this. It was clear in quotations I already gave before that he (unlike Borg) is careful not to assume that a semantic theory by itself can serve as a fully-fledged theory of reference and truth condition determination (although he does not assume the opposite either). Laudably, he also puts aside Davidsonian prejudices on this matter, contending that reference is not just an instrumental theoretical posit (p. 59), 
and offering instead in chapter 7 a very interesting elaboration on file-theoretic accounts of mental reference, compatible with RWR, well-informed by recent results in cognitive science.

Nevertheless, he still finds a place for idealization in dealing with this second problem for truth-theoretic accounts: "even if semantics falls short of truth conditions, the truth-conditional approach constitutes a useful idealization" (p. 50); "even if they involve a large dose of idealization, [truth-theoretic approaches] can still show why there is no need to think of meaning as entities, and by their focus on compositional features, help deter ad hoc "analyses" (p. 59). I find this appeal to idealization as questionable as the previous one, because, as before, I think it masks the need for a more genuinely explanatory account of the facts at stake. As I suggested before, a more illuminating account of this kind would be closer to more traditional Fregean descriptivism than RWR allows.

Sainsbury has a brilliant critical section on descriptivist alternatives to RWR, an epitome of the main virtues of the book; it is short, but it covers the main issues incisively, concluding thus:

The usual anti-descriptivist considerations can be worked into a dilemma: either the proffered descriptions are inconstant, either across time or across speakers, in which case for that reason alone they do not do justice to the constant and interpersonal public meaning; or they are constant, in which case they will typically be metalinguistic, and will be too sophisticated to be plausible candidates for what a good reporter should use in place of her subject's names. (p. 105)

This certainly sums up a very forceful objection, to which I cannot do any justice here. Instead, and as in the previous case, I would like to sketch the alternative descriptivist account I would like to be able to defend from criticisms such as Sainsbury's, just to make clear to what extent the appeal to idealization covers up the shortcomings of the truth-theoretic proposal.

As I said, in chapter 7 Sainsbury helpfully elaborates on accounts of reference that appeal to the metaphor of mental files to characterize individual concepts. Although he suggests that this proposal about mental reference is not an essential part of RWR, at several points in the book mental reference is helpfully appealed to; for instance, the chapter on referring indexicals and demonstratives concludes that understanding referring expressions "involves using an individual concept created by a mechanism whose survival is owed to its producing concepts with individual objects as their referent, 
so cases in which the individual concept lacks a referent are typically cases of malfunction" (p. 169); we also find in that same chapter the claim that "when all goes as it should, interpreting a referring expression involves an identity judgment, typically implicit, in which an interpretation-independent way of identifying the referent is coordinated with an interpretation-dependent way" (p. 157).

I find all of this very suggestive. In terms of the metaphor of mental files, making an identity judgment is adding together in one and the same file two pieces of descriptive information; in the case Sainsbury is envisaging, it would be a matter of putting together in one and the same file the metalinguistic information provided by applying the linguistic knowledge that, I suggested before, a better theory than truth-theoretic accounts should provide, to the effect, say, that the referent of the mental concept is a horse contextually salient when the token of "that horse" was uttered, with, say, the information (perhaps in the format of visual representations) that it is located at such-and-such a position in egocentric space and looks such-and-such. This would be the beginning of an explanation why, against Borg's (2004) minimalist proposal, the information derived only from linguistic competence is typically not enough for understanding truth conditions in general and reference in particular, but is at least a crucial part of that understanding. I would like to think that an account along these lines can deal with the anti-descriptivist considerations that Sainsbury summarizes; for the case of proper names, as the parallel before between (7) and (9) is intended to suggest, the metalinguistic part provided by linguistic competence would be something like person contextually named when that token of " $N$ " was used. ${ }^{3}$ The descriptions required to interpret referential expressions would then not typically be constant across speakers and times, but would be just one more instance of the intrusion of context in linguistic communication; they would have at their core, however, a metalinguistic part given by linguistic competence. A proper elaboration of the file metaphor, in the shape of an acceptable theoretical account of mental concepts, should help to dispel the concern voiced by Sainsbury in the above quotation, by providing an account of the implicit knowledge that competent speakers have of the relevant metalinguistic descriptions.

\footnotetext{
${ }^{3}$ I say "contextually named" as opposed to simply "named" because of contexts where more than one naming practice related to the same name-type is presupposed. Cf. Pelczar 2001 for a view which I find rather congenial.
} 
Once again, I only make these sketchy claims in order to question what I take to be the insufficiencies of RWR, which I feel the appeal to idealization merely hides. An account along the lines suggested could put us in a position to explain why the replacement of "Hesperus" with "Phosphorus" on the right hand side of axiom (1) would indeed lead to a non-interpretive theory; where the homophonic proposal, by relying on our merely implicit and theoretically inadequate knowledge of why this is so, leaves us simply mystified. We already saw why abandoning reductive ambitions is compatible with the provision of genuinely explanatory information in the case of indexicals, and as I said I cannot see any relevant difference in the case of proper names. Even more importantly for RWR, an account along the above lines would be much more satisfactory when it comes to justifying its main tenets about empty referential expressions and concepts, in particular when it comes to explaining why utterances including "Vulcan" can be intelligible, and in some cases even true.

So far I have been questioning the explanatory adequacy of the Davidsonian framework relative to which the main claims about reference in RWR are made, from an essentially friendly perspective on the problems, and extolling by way of contrast the merits of an alternative, slightly more ambitious account. I will conclude with two final criticisms of RWR. The first concerns the explanation of rigidity; the second, the choice of free logic. In both cases, I will also follow my previous strategy of outlining an alternative proposal.

Against traditional descriptivist accounts of the thoughts expressed by utterances including literally used proper names or indexicals, and referentially used descriptions, Kripke and others marshalled "intuitions of rigidity", such as that when we consider possible states of affairs compatible with the truth of a given utterance, we keep fixed the denotation of the referential expression in the actual state of affairs, if any: "My main remark [...] is that we have a direct intuition of the rigidity of names, exhibited in our understanding of the truth conditions of particular sentences" (Kripke 1980, p. 14; cf. also pp. 6, 62). According to Sainsbury (2005, pp. 76-81), the explanation for the datum of rigidity is given by the "essence of reference", which on his view is captured by Evans's principle $(\mathrm{P})$ :

(P) If $S$ is an atomic sentence combining the $n$-place conceptexpression $R$ with singular terms $t_{1} \ldots t_{n}$, then $S$ is true iff $<$ the referent of $t_{1} \ldots$ the referent of $t_{n}>$ satisfies $R$.

However, I do not think this principle can adequately carry the explanatory burden. The restriction to atomic sentences is intended 
to exclude sentences formed with definite descriptions used "attributively", as quantifiers; and the metalinguistic descriptions used in the principle must be interpreted as referring expression themselves, or alternatively rigidified by inserting "actual", for the principle to deliver the intuitively correct rigid truth-conditions. In both respects, in order to obtain the intuitively desired results from the principle, we must apply it in accordance with the distinction we are trying to account for. On my own view, the explanation should be given by appealing to the presuppositional character of the descriptive information. As Sainsbury puts it, "The essential role of a referring expression is given by the fact that, normally, in using it in a simple sentence, a speaker represents himself as aiming to introduce an object $[\ldots]$ for the rest of the sentence to say something about" (p. 81). A proper account of rigidity should in my view develop the point that, given that this is so, the identifying information that the speaker relies on plays merely a presuppositional, background role.

The final question I would like to raise concerns the choice of free logic. Compare (10)-(14), for which I give existentially hedged and unhedged versions:

(10) Vulcan is bigger than Mars.

(11) Vulcan causes perturbations in Mercury's orbit (if it exists).

(12) Vulcan is identical to itself (if it exists).

(13) Vulcan is bigger than Mars, or it is not bigger than Mars (if it exists).

(14) Vulcan exists.

I assume that our intuitive judgments are as follows: (10) is untrue, and the same applies to its negation, or at least we are reluctant to judge it straightforwardly false; (14) is false, and its negation true; the hedged versions of (11)-(12) are true; we are unclear about the unhedged versions, but are inclined to count them as true. To count (12) and (13) as true, at least in their hedged versions, but (14) as false (on the straightforward formalizations), we need a free logic, free from existence assumptions with respect to the singular terms, while keeping them for existential quantifiers.

Sainsbury follows Burge (1974) in choosing a negative free logic, on which all atomic sentences are false. However, as Lehmann (2002, 
p. 226) notes, Burge's justification for his choice presupposes bivalence, and the same applies to Sainsbury's. I myself prefer a positive free logic, on which some atomic sentences (in particular, the unhedged (12)) are true. I agree with Sainsbury that the justification for such a choice cannot depend only on intuitions and has to be ultimately one of best global theoretical fit. I would argue that (11)(13) are cases of the general phenomenon that Yablo (2006) calls "non-catastrophic presupposition failure", as in (15)-(16) - cases unlike "the King of France is bald", where, as Strawson put it, "the assertoric enterprise is wrecked". A presupposition of an assertoric utterance plays only an ancillary, background role vis-à-vis its assertoric content. This motivates the basic idea to account for these cases, that an assertion made with a sentence with a false presupposition counts as false if its falsity is determined by the falsity of some of its entailments independent of the presupposition (for (15), I had breakfast with a king/somebody is sitting in that chair); it counts as true if its truth is determined by the truth of some proposition independent of the presupposition entailing it (for (16), all of Sants station's newsstands sell the Guardian):

(15) I had breakfast with the King of France / the King of France is sitting in that chair.

(16) They sell the Guardian at the Sants station's newsstand.

But I should acknowledge that it is no easy task to articulate an intuitively satisfactory general account (cf. in addition von Fintel 2004, Bezuidenhout forthcoming), in part because our intuitions are sensitive to pragmatic aspects such as discourse topic and focus; and it is not easy either to justify on this basis the supervaluationist semantics, even assuming that we have one. Fortunately, as before I am more interested here in questioning RWR's proposal.

I have two qualms in this regard. The first is again about explanation. Negative free logics count as false the simple sentence "Vulcan is identical to itself", and as true its negation. However, "Vulcan is distinct from itself" counts as false, assuming it is also atomic. Sainsbury has to contend that the two are not synonymous - and the same applies to all similar cases. This sounds a bit ad hoc, even if ultimately justifiable on the basis of global theoretical fit.

My second problem is about Sainsbury's criticism of the usual justification for the positive free logic take on the unhedged (12), based on the logical truth that everything is self-identical. He rightly 
says that simply taking the logical generalization as the claim that each object is self-identical will not do for the envisaged justification, "for there is no such object as Vulcan" (p. 66). The logical principle should rather be taken as telling us

something about expressions, for example, that every sentence composed of two occurrences of the same singular term, separated by the identity sign, is true. This makes it plain that we are not dealing with a genuinely logical principle, but with some metalinguistic opinion about referring expressions. This opinion is dubious independently of empty names. There are false instances of " $x=x$ ", and true instances which cannot be known apriori (and so fail a familiar test for counting as logical (p. 67)

he goes on to provide examples of the "Paderewski is Paderewski" kind to make this latter point.

My objection to this is that there is a third alternative. Formal languages are stipulated to be so that tokens of the same expressions receive the same interpretation. "Aristotle is Aristotle" is not interpreted in natural languages with that restriction; when it is not interpreted in that way, its logical form is not given by " $a=a$ ", but rather by " $a=b$ ". The same applies to all other logical principles, of course; without the restriction, the logical form of "if Aristotle is Greek, then Aristotle is Greek" is not "Pa $\supset \mathrm{Pa}^{\prime}$, and it is not a logical truth either. "Vulcan is identical to itself" does have in natural languages the logical form given by " $a=a$ ". Whether or not it should be counted as true, I acknowledged, cannot be decided merely on the basis of intuitions; but that it is so, in that it is an instance of the principle that every object is identical to itself, is not the ungrounded metalinguistic opinion that Sainsbury makes it seem. How natural languages codify principles about the relation between the interpretations of expressions, and how those relations should be taken into account in providing accurate formalizations (logical forms) for them is again no simple matter; but Sainsbury himself needs them, because, I assume, he wants to count proper instances of the hedged versions of (12) as logical truths, but they can be objected with the "Paderewski"-like cases as much as the unhedged versions can.

In this article I have presented some small concerns raised by RWR from a fundamentally sympathetic perspective, which I have had to outline more than perhaps is proper because, ultimately, there is no other way of deciding between the several options than on the basis of general theoretical considerations. More than that, I hope I 
have also given some idea of how rich, rewarding, thought-provoking and deeply illuminating Sainsbury's work is. ${ }^{4}$

\section{REFERENCES}

Barker, S., 2003, "Truth and Conventional Implicature", Mind, vol. 112, pp. 1-33.

Bezuidenhout, A., forthcoming, "Presupposition Failure and Assertoric Inertia", in M. Hackl and R. Thornton (eds.), Asserting, Meaning, and Implying, Oxford University Press, Oxford.

Borg, E., 2004, Minimal Semantics, Oxford University Press, Oxford.

Burge, T., 1974, "Truth and Singular Terms", Noûs, vol. 8, pp. 309-325.

García-Carpintero, M., 2006a, "Two-Dimensionalism: A Neo-Fregean Interpretation", in M. García-Carpintero and J. Macià (eds.), 2006, TwoDimensional Semantics, Oxford University Press, Oxford, pp. 181-204.

— 2006b, "Recanati on the Semantics/Pragmatics Distinction", Críti$c a$, vol. 38, no. 112, pp. 35-68.

- 2000, "A Presuppositional Account of Reference-Fixing", Journal of Philosophy, vol. 97, no. 3, pp. 109-147.

— , forthcoming, "Fictional Singular Imaginings", in R. Jeshion (ed.), New Essays on Singular Thought, Oxford University Press, Oxford.

Grice, H.P., 1989, Studies in the Ways of Words, Harvard University Press, Cambridge, Mass.

Heim, I., and A. Kratzer, 1998, Semantics in Generative Grammar, Blackwell, Oxford.

Kaplan, D., 1989, “Demonstratives”, in J. Almog, J. Perry and H. Wettstein (eds.), Themes from Kaplan, Oxford University Press, Oxford, pp. 481563.

Kripke, S., 1980, Naming and Necessity, Blackwell, Oxford.

Larson, R. and G. Segal, 1996, Knowledge of Meaning: Semantic Value and Logical Form, MIT Press, Cambridge, Mass.

Lehmann, S., 2002, "More Free Logic", in Gabbay, (ed.), Handbook of Philosophical Logic, 2nd ed., vol. 5, Kluwer Academic Publishers, ciudad, pp. 197-259.

Pagin, P. and J. Pelletier, 2007, "Content, Context and Composition", in G. Peter and G. Preyer (eds.), Context-Sensitivity and Semantic Minimalism, Oxford University Press, Oxford, pp. 25-62.

Pelczar, M.W., 2001, "Names as Tokens and Names as Tools", Synthese, vol. 128, pp. 133-155.

${ }^{4}$ I thank Teresa Marques for comments on a previous version which led to improvements and Michael Maudsley for his grammatical revision. Financial support for my work was provided by the DGI, Spanish Government, research project HUM2006-08236, and the DURSI, Distinció de Recerca 2002. 
Sainsbury, M., 2005, Reference without Referents, Oxford University Press, Oxford.

Stalnaker, R., 2002, "Common Ground", Linguistics and Philosophy, vol. 25, pp. 701-721.

Stalnaker, R., 1978, “Assertion”, in P. Cole (ed.), Syntax and Semantics, vol. 9, Academic Press, New York, pp. 315-332. Also in R. Stalnaker, 1999, Context and Content, Oxford University Press, Oxford, pp. 78-95. , 1974, "Pragmatic Presuppositions", in M.K. Munitz and P.K. Unger (eds.), Semantics and Philosophy, New York University Press, New York.

von Fintel, K., 2004, "Would You Believe It? The King of France is Back! (Presuppositions and Truth-Value Intuitions)", in M. Reimer and A. Bezuidenhout (eds.), Descriptions and Beyond, Oxford University Press, Oxford, pp. 269-296.

Yablo, S., 2006, "Non-Catastrophic Presupposition Failure", in J. Thomson and A. Byrne (eds.), Content and Modality: Themes from the Philosophy of Robert Stalnaker, Clarendon Press, Oxford, pp. 164-190.

Received: October 21, 2008; accepted: November 5, 2008. 